\title{
How quickly do cloud droplets form on atmospheric particles?
}

\author{
C. R. Ruehl ${ }^{1}$, P. Y. Chuang ${ }^{1}$, and A. Nenes ${ }^{2,3}$ \\ ${ }^{1}$ Earth \& Planetary Sciences, University of California, Santa Cruz, California, USA \\ ${ }^{2}$ Earth \& Atmospheric Sciences, Georgia Institute of Technology, Atlanta, Georgia, USA \\ ${ }^{3}$ Chemical and Biomolecular Engineering, Georgia Institute of Technology, Atlanta, Georgia, USA
}

Received: 25 September 2007 - Published in Atmos. Chem. Phys. Discuss.: 8 October 2007

Revised: 22 January 2008 - Accepted: 28 January 2008 - Published: 27 February 2008

\begin{abstract}
The influence of aerosols on cloud properties is an important modulator of the climate system. Traditional Köhler theory predicts the equilibrium concentration of cloud condensation nuclei $(\mathrm{CCN})$; however, it is not known to what extent particles exist in the atmosphere that may be prevented from acting as $\mathrm{CCN}$ by kinetic limitations. We measured the rate of cloud droplet formation on atmospheric particles sampled at four sites across the United States during the summer of 2006: Great Smoky Mountain National Park, TN; Bondville, IL; Houston, TX; and the Atmospheric Radiation Measurement Program Southern Great Plains site near Lamont, OK. We express droplet growth rates with the mass accommodation coefficient $(\alpha)$, and report values of $\alpha$ measured in the field normalized to the mean $\alpha$ measured for lab-generated ammonium sulfate (AS) particles (i.e., $\alpha^{\prime}=\alpha / \alpha_{\mathrm{AS}}$ ). Overall, $59 \%$ of ambient $\mathrm{CCN}$ grew at a rate similar to AS. We report the fraction of CCN that were "low- $\alpha^{\prime \prime}$ " $\left(\alpha^{\prime}<10^{-1}\right.$, corresponding to $\left.\alpha<1.5 \times 10^{-2}\right)$. Of the 16 days during which these measurements were made, 8 had relatively few low- $\alpha^{\prime}$ CCN $(<16 \%), 6$ had moderate low- $\alpha^{\prime}$ fractions (27\% to $59 \%$ ), and 2 had large low- $\alpha^{\prime}$ fractions ( $>82 \%$ during at least one $\sim 30$ min period). Day to day variability was greatest in Tennessee and Illinois, and low- $\alpha^{\prime}$ particles were most prevalent on days when back trajectories suggested that air was arriving from aloft. The highest fractions of low- $\alpha^{\prime} \mathrm{CCN}$ in Houston and Illinois occurred around local noon, and decreased later in the day. These results suggest that for some air masses, accurate quantification of $\mathrm{CCN}$ concentrations may need to account for kinetic limitations.
\end{abstract}

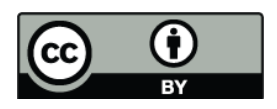

Correspondence to: C. R. Ruehl (cruehl@ucsc.edu)

\section{Introduction}

After several decades of research attempting to quantify the influence of human activities on the Earth's climate, the largest single source of uncertainty in the total anthropogenic radiative forcing of the atmosphere remains the effect of atmospheric particles on cloud properties, i.e., the indirect aerosol effects on climate (IPCC, 2007). The ability to predict the size distribution of cloud droplets given an initial size distribution of suspended particles is essential if aerosol indirect effects are to be quantified. In the atmosphere, cloud droplets form on pre-existing aerosol particles, which can act as cloud condensation nuclei $(\mathrm{CCN})$ when the ambient partial pressure of water vapor $\left(p_{w}\right)$ exceeds the saturation vapor pressure $\left(p_{w}^{0}\right)$ resulting in a supersaturation $(S)$

$S=\frac{p_{w}}{p_{w}^{0}}-1$.

For almost a century, Köhler theory (Köhler, 1936) has been used to determine the minimum, or critical, supersaturation $\left(S_{c}\right)$ required to activate a particle of known size and composition, causing the particle to grow into a cloud droplet via condensation of water vapor. More recently, modifications of Köhler theory have been proposed to incorporate various chemical effects, including slightly-soluble compounds (Shulman et al., 1996), soluble gases (Kumala et al., 1993), surface tension reduction (Shulman et al., 1996; Facchini et al., 1999), and film-forming compounds (Feingold and Chuang, 2002). Adiabatic cloud parcel modeling suggests that the influence of these effects on cloud droplet concentration $\left(N_{d}\right)$ is comparable to the influence of total particle concentration (Nenes et al., 2002).

Classical Köhler theory, however, predicts only the equilibrium $S_{c}$ of a particle, and thus does not incorporate any potential kinetic limitations to cloud droplet formation. Chuang et al. (1997) pointed out that failure to take into account kinetic limitations could result in errors in calculated

Published by Copernicus Publications on behalf of the European Geosciences Union. 
radiative forcing similar to that corresponding to current anthropogenic greenhouse gas concentrations $\left(\sim 2 \mathrm{~W} / \mathrm{m}^{2}\right)$. It is therefore of interest if particles exist in the atmosphere that, under typical atmospheric supersaturations $(\sim 0.1$ to $1 \%)$, would form cloud droplets at equilibrium, but cannot do so within realistic time scales (tens of seconds to a few minutes). These kinetic limitations could result from, for example, films at the droplet surface that limit transfer of water to the drop during condensation, or from slow dissolution of particulate matter. The kinetics of condensational growth are often represented by the mass accommodation coefficient $(\alpha)$, which conceptually is the probability that a water vapor molecule colliding with a droplet will be incorporated into the liquid phase. Although $\alpha$ for pure water droplets is expected to be $\sim 1$ (Laaksonen, 2005), some experimental techniques have yielded estimates of $\alpha$ for pure water as low as 0.06 (Shaw and Lamb, 1999). Regardless, it is not known to what extent the atmosphere contains CCN whose growth rates during activation would be better fit using standard condensational growth theory with $\alpha$ less than that expected for pure water. A great number of studies have concluded that the presence of an organic film at the aqueousair interface can reduce $\alpha$ during condensation and/or evaporation to $\sim 10^{-4}$ (e.g., Rubel and Gentry, 1984; Seaver et al., 1992). Cantrell et al. (2001) found that setting $\alpha$ equal to $10^{-4}$ produced the best fit between modelled and measured CCN concentrations near the Indian Ocean during a time when aerosol concentrations and organic fractions were relatively high. Chuang (2003) found that 0 to $2 \%$ of particles in Mexico City exhibited subsaturated condensational (i.e., hygroscopic) growth at a rate corresponding to $\alpha \sim 1$ to $4 \times 10^{-4}$, but did not measure growth rates under supersaturated (i.e., droplet activating) conditions. Recently, Stroud et al. (2007) found that setting $\alpha$ equal to 0.07 produced the best fit between modeled growth and that observed for $\mathrm{CCN}$ sampled from a forest in the southeastern United States. In this study, we determine $\alpha$ for each observed activated droplet at realistic $S$ values ( 0.13 to $0.63 \%)$, and thus determine the $\alpha$ distribution of atmospheric $\mathrm{CCN}$.

Köhler theory can be tested by $\mathrm{CCN}$ closure experiments, in which $\mathrm{CCN}$ concentration $\left(N_{\mathrm{CCN}}\right)$ predicted given particle size distribution and composition is compared to observations in a CCN instrument in which $S$ is known. Closure experiments have been conducted in various settings, including near the Canary Islands, Spain (Snider and Brenguier, 2000; Chuang et al., 2000), the Southern Ocean (Covert et al., 1998), the Arctic Ocean (Zhou et al., 2001), the Indian Ocean (Cantrell et al., 2001), Amazonia (Rissler et al., 2004), Florida (VanReken et al., 2003), Nova Scotia (Ervens et al., 2007), New Hampshire (Medina et al., 2007), and North Carolina (Stroud et al., 2007). A smaller number of studies have compared predicted and observed in-situ cloud droplet concentrations (e.g., Hallberg et al., 1997; Snider et al., 2003; Conant et al., 2004). Although closure is often achieved within experimental uncertainties, when it is not achieved it is almost invariably due to overprediction of $\mathrm{CCN}$ concentrations. Often discrepancies between predictions and observations can only be reduced by assuming that the aerosol soluble fraction is unrealistically low (e.g., Snider and Brenguier, 2000), or alternatively that all aerosol organic matter is insoluble (e.g., Cantrell et al., 2001), despite observations that some organic aerosol is CCN active (e.g., Novakov and Penner, 1993). These discrepancies could be due to kinetic limitations to droplet growth, a possibility that seems more likely considering that most identified chemical effects on droplet activation lower $S_{c}$ (e.g., surface tension reduction and dissolution of gases). If kinetic limitations to cloud droplet formation are important in the atmosphere, not only cloud properties but also the lifetime of aerosol particles and consequently aerosol composition could be influenced. The purpose of this study was to measure $\alpha$ distributions for various ambient aerosols (urban, regional polluted, and background) to determine the extent to which potential kinetic limitations to droplet formation exist in the atmosphere.

\section{Experimental}

\subsection{Site descriptions}

All equipment was housed in a trailer, which was deployed at four sites across the United States during August-September 2006 (Fig. 1). The sites were selected to sample a variety of general air mass types: urban (HOU - Houston, TX), polluted regional (GSM - Great Smoky Mountain National Park, TN), and background continental (BON - Bondville, IL, and SGP - the Southern Great Plains site, run by the U.S. Department of Energy Atmospheric Radiation Measurement program, near Lamont, OK). In Houston, particles were sampled on top of Moody Towers on the campus of the University of Houston, as part of the second Texas Air Quality Study (TexAQS II). Moody Towers is approximately $6 \mathrm{~km}$ southeast of downtown Houston, and $5 \mathrm{~km}$ southwest of the Houston Ship Channel. $\mathrm{PM}_{2.5}$ in the region is dominated by sulfate (32\% by mass), organic carbon $(30 \%)$, and ammonium (9\%), and annual mean $\mathrm{PM}_{2.5}$ concentrations are 10 to $14 \mu \mathrm{g} / \mathrm{m}^{3}$, with maximum hourly concentrations often $>40 \mu \mathrm{g} / \mathrm{m}^{3}$ (Russell et al., 2004). The GSM site was located at Look Rock, a long-term atmospheric monitoring station on a ridge along the western edge of the National Park. To the north and west of this ridge is a valley that includes the cities of Knoxville ( $36 \mathrm{~km}$ north) and Chattanooga (140 km southwest), as well as several interstate highways and coal-fired power plants. During the summer of 2001, the average $\mathrm{PM}_{2.5}$ concentration at Look Rock was $19.0 \mu \mathrm{g} / \mathrm{m}^{3}$, which by mass was $41 \%$ sulfate, $29 \%$ organic carbon, and $9 \%$ ammonium (Tanner et al., 2004). The BON site was at the Bondville Environmental and Atmospheric Research Site, maintained by the Illinois State Water Survey, $14 \mathrm{~km}$ southwest of UrbanaChampaign. Throughout a field campaign conducted at BON 

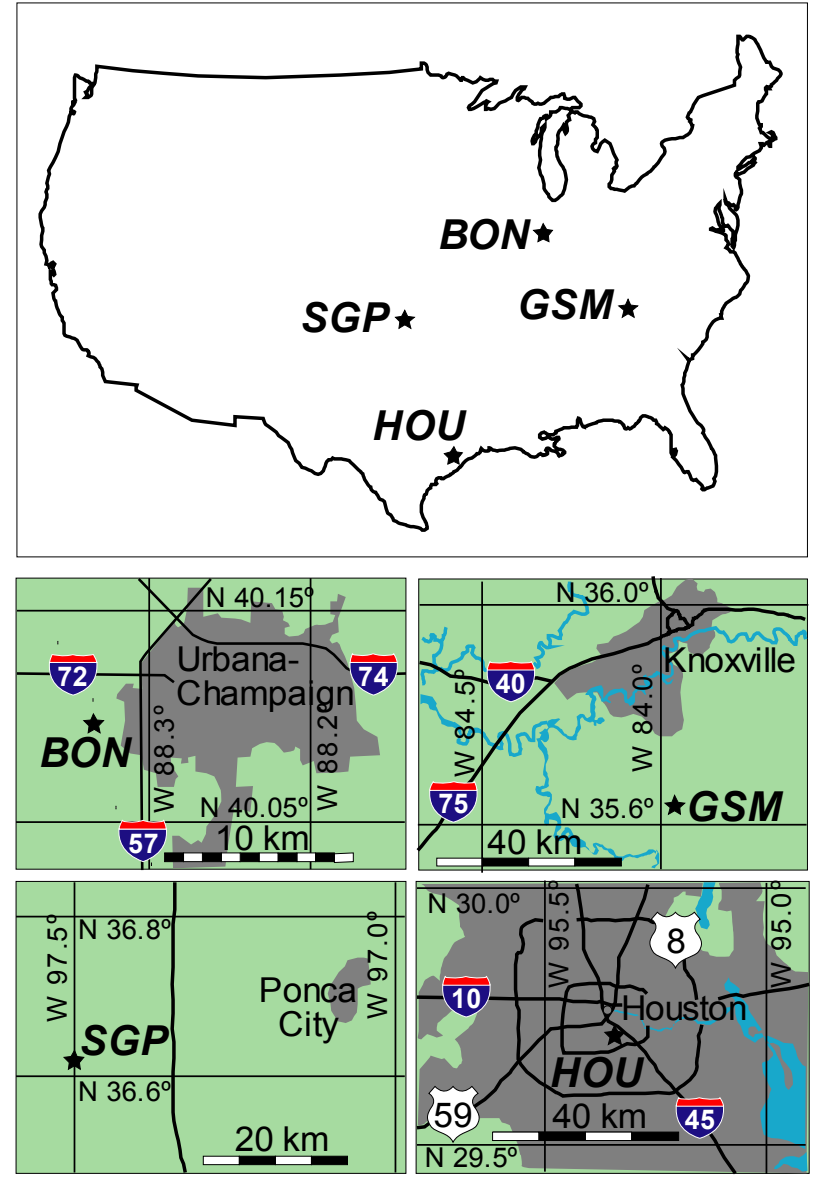

Fig. 1. United States map, showing locations of urban (HOU), polluted regional (GSM), and background continental (BON and SGP) sites, along with inset maps of each site.

from March 2001 to May 2003, the average $\mathrm{PM}_{2.5}$ concentration was $9.5 \mu \mathrm{g} / \mathrm{m}^{3}$, of which (by mass) $12 \%$ was organic carbon, $28 \%$ was sulfate, and $17 \%$ was nitrate (Kim et al., 2005). The Southern Great Plains (SGP) site, located $38 \mathrm{~km}$ southwest of Ponca City, OK, is maintained by the U.S. Department of Energy's Atmospheric Radiation Measurement Program. Summer submicron aerosol at the site from 1997 through 2001 was dominated by sulfate and ammonium (23 to $30 \%$ and 9 to $12 \%$ by mass, respectively), and concentrations averaged $12.1 \mu \mathrm{g} / \mathrm{m}^{3}$ (organic carbon was not quantified) (Iziomon and Lohmann, 2003).

\subsection{Instrumentation}

Condensational growth rates were measured for both generated ammonium sulfate (AS) particles, used as reference particles, and ambient particles sampled in the field. This was accomplished by exposing particles to a water vapor supersaturation (i.e., $S>0$ ) for a known duration in a Continuous Flow Thermal Gradient Chamber (CFTGC), and then mea-

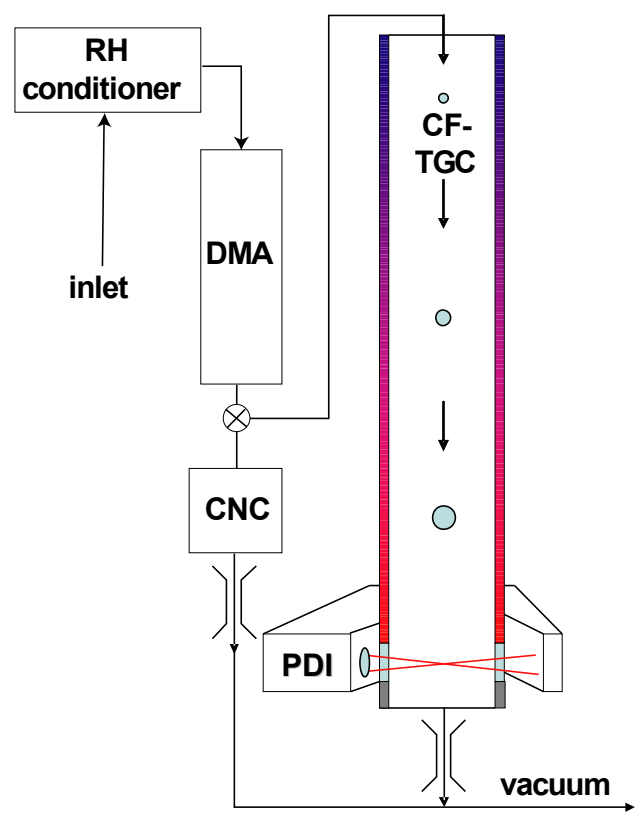

Fig. 2. Experimental schematic.

suring the resulting droplet size with a phase doppler interferometer (PDI). The CFTGC produces a water vapor supersaturation along its centerline when an increasing temperature gradient $(\Delta T)$ is applied to its walls (Fig. 2). Both $S$ and the duration of the exposure can be controlled by adjusting the CFTGC flow rate and $\Delta T$ (Roberts and Nenes, 2005). Particles were initially passed through a humidity conditioner that maintained the relative humidity $(\mathrm{RH})$ at $>80 \%$. The particles were then sent to a differential mobility analyzer (DMA). The DMA sheath flow was taken from the sample stream and filtered to ensure that it had a similar RH and $T$ as the DMA sample flow. The DMA selected a quasimonodisperse particle population with a mean diameter in the range of 100 to $250 \mathrm{~nm}$. This flow was then divided between a condensation nucleus counter (CNC, TSI 3010) and the CFTGC-PDI. After flowing for $10 \mathrm{~s}$ through a wetted isothermal entrance length with $\mathrm{RH} \sim 100 \%$, particles were exposed to a known $S$ in the CFTGC for $30 \mathrm{~s}$. The velocity and diameter $(D)$ of the activated droplets was then measured with the PDI while still subject to $S$ (i.e., before the particles exited the CFTGC).

Along the centerline of the CFTGCC, the calibrated value of $S$ at any given $\Delta T$ is determined by the mobility diameter of lab-generated AS particles selected by the DMA at which $50 \%$ are activated. Under the DMA conditions used for this calibration, the geometric standard deviation of the DMA transfer function is approximately 1.05 , which corresponds to an absolute uncertainty in $S_{c}$ of $0.01 \%$ at the low end of the calibration $(0.11 \%)$ and $0.04 \%$ at the high end $(0.63 \%)$. Temperature fluctuations in the CFTGC were monitored with thermistors and were typically $\sim 0.01 \mathrm{~K}$, which 
would produce a negligible uncertainty in $S$ relative to the uncertainty associated with the DMA transfer function. Likewise, CFTGC flow rate fluctuations are expected to be minimal, as this flow passed through a critical orifice immediately downstream of the column. However, there were at times substantial variations in the droplet velocity measured by the PDI, possibly due to deviations from a fully-developed (parabolic) velocity profile in the CFTGC in the vicinity of the PDI view volume. We therefore omitted any measurements in which the PDI velocity was more than 5\% higher or lower than that predicted for parabolic flow. These were typically $<20 \%$ of all measurements, and tended to occur immediately after changing the temperature gradient in the column, and/or when $\Delta T$ was relatively high $(\sim 20 \mathrm{~K} / \mathrm{m})$. The resulting uncertainty in droplet size due to velocity fluctuations is minimized, however, because when the droplet velocity is greater, the $S$ experienced for a given $\Delta T$ increases (enhancing droplet growth), whereas the residence time in the CFTGC decreases (inhibiting droplet growth). Therefore, uncertainty in droplet growth rate based on measurements of $D$ are expected to be less than those associated with the $<5 \%$ deviation from parabolic flow velocity discussed above.

There are several advantages to using a phase Doppler interferometer to measure droplet diameter. Conventional light-scattering probes direct a single laser beam into a stream of particles, which scatter light when they intersect the beam. The diameter is determined by the intensity of the scattered light signal. A PDI, on the other hand, consists of two laser beams that form a view volume at their intersection (Bachalo, 1980; Bachalo and Houser, 1984; Bachalo and Sankar, 1996), which in this system is on the centerline of the CFTGC. When droplets pass through this view volume, three photodetectors aligned along the axis of the CFTGC measure the light scattered by the droplet. The phase differences between the photodetector signals are determined by the curvature of the droplet (a function of $D$ ), because the divergence of scattered light increases as the droplet curvature increases. Therefore the $D$ measurement depends only on these phase differences, and is independent of signal intensity. This is an advantage because signal intensity can be influenced by detector response, laser strength, and absorption/scattering of light by condensation on CFTGC windows or smaller droplets off the CFTGC centerline, all of which can vary with time. We therefore were able to place the view volume in the CFTGC while the droplets were still exposed to $S$ by aligning the beams and photodetectors with windows that were built into the CFTGC, and any minor condensation on the windows did not influence diameter measurements. The PDI probe used in these experiments was calibrated with precision glass beads of known $D$, and can detect droplets with $D \geq 0.5 \mu \mathrm{m}$, with an accuracy of $\pm 0.5 \mu \mathrm{m}$ (Sankar et al., 1991). We assume that the droplets were still exposed to the average centerline $S$ when they passed through the view volume even though the temperature gradient ended $\sim 2 \mathrm{~cm}$ above the windows. This is because water vapor and heat dif- fusing from the inner wall of the CFTGC to the centerline are also carried downwards by the flow in the CFTGC. Droplets in the view volume experience a water vapor pressure equal to that along the wall some distance above the view volume. This distance $(x)$ is roughly equal to the product of the average velocity inside the CFTGC ( $\bar{v}_{\text {CFTGC }}$ ) and the timescale of water vapor diffusion $\left(\tau_{w}\right)$ (Roberts and Nenes, 2005)

$x=\bar{v}_{\mathrm{CFTGC}} \tau_{w}=\frac{\bar{v}_{\mathrm{CFTGC}} R_{\mathrm{CFTGC}}^{2}}{D_{v}}$

where $R_{\text {CFTGC }}$ is the inner radius of the CFTGC $(0.011 \mathrm{~m})$ and $D_{v}$ is the diffusivity of water vapor in air $\left(2.5 \times 10^{-5} \mathrm{~m}^{2} / \mathrm{s}\right.$ at $298 \mathrm{~K}$ and $1 \mathrm{~atm})$. All results presented here are for $\bar{v}_{\mathrm{SSC}}=0.011 \mathrm{~m} / \mathrm{s}$, which when used in Eq. (3) results in $x>5 \mathrm{~cm}$, suggesting that the droplets in the view volume are still experiencing the characteristic $S$ of the CFTGC. Additionally, the PDI ensures that only droplets along the CFTGC centerline are measured (the view volume dimensions are less than $1 \mathrm{~mm}$ perpendicular to the direction of sample flow), i.e., droplets are exposed to a single (maximum) $S$. Finally, as discussed above, the PDI also determines droplet velocity based on the frequency of the scattered light signal, and thus we were able to verify that parabolic flow had developed in the CFTGC and consequently to minimize uncertainty in the CFTGC residence time.

\subsection{CFTGC model}

We represent droplet growth rates by transforming observed drop size distributions into $\alpha$ distributions with a fullycoupled numerical flow model that simulates conditions in the CFTGC (Roberts and Nenes, 2005). This model calculates the final $D$ given initial particle composition and size, $\alpha, \Delta T$ (which determines $S$, based on calibration with dry ammonium sulfate particles) and flow rate (i.e., duration of exposure to $S$ ). The model solves the time-dependent equations for droplet condensational growth in a water vapor supersaturation (Fukuta and Walter, 1970)

$$
D \frac{d D}{d t}=\frac{S-S_{\mathrm{eq}}}{\frac{\rho_{w} R T}{4 p_{w}^{0} D_{v}^{\prime} M_{w}}+\frac{\rho_{w} M_{w} \Delta H_{v}}{4 k^{\prime} T}\left(\frac{\Delta H_{v}}{R T}-1\right)}
$$

where $S_{\text {eq }}$ is the equilibrium supersaturation of the particle (i.e., the solution to the Köhler equation), $\rho_{w}, M_{w}$, and $\Delta H_{v}$ are the density, molecular mass, and molar heat of vaporization of water, $R$ is the universal gas constant, $T$ is the temperature, and $D_{v}^{\prime}$ and $k^{\prime}$ are the diffusivity and thermal conductivity of water vapor corrected for noncontinuum effects. The size of this correction for $D_{v}^{\prime}$ depends on $\alpha$ (Fukuta and Walter, 1970)

$$
D_{v}^{\prime}=\frac{D_{v}}{1+\frac{2 D_{v}}{\alpha D} \sqrt{\frac{2 \pi M_{w}}{R T}}} .
$$

Our direct measurement is of the droplet growth rate. We parameterize the results with $\alpha$, but we are not able to determine if limited mass transfer is the mechanism causing some 


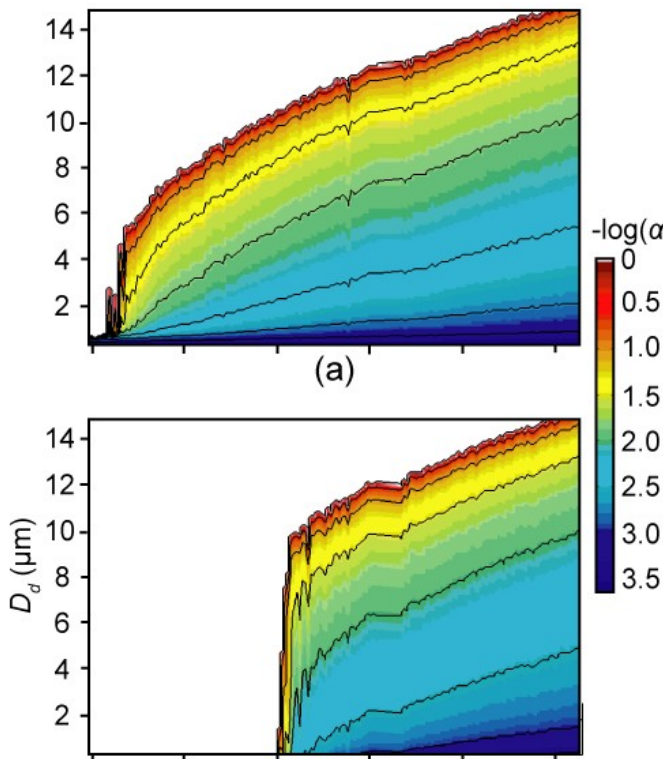

(b) $\Delta \log (\alpha)$

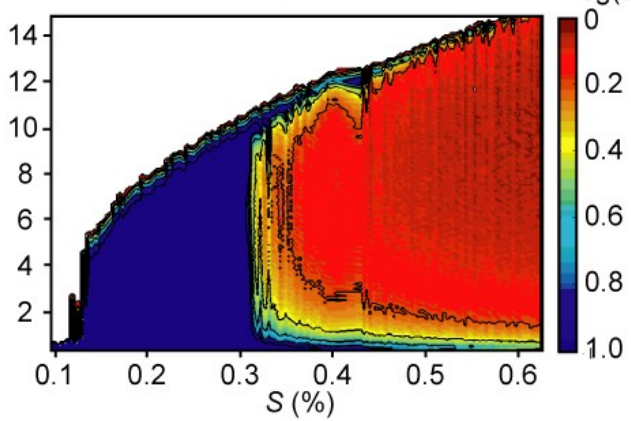

(c)

Fig. 3. (a) $\alpha(S, D)$ for $30 \mathrm{~s}$ of droplet growth on ammonium sulfate particles $\left(100 \%\right.$ soluble) with $D_{\text {dry }}=100 \mathrm{~nm}$. (b) Same as (a), but with 5\% soluble particles. (c) Difference between (a) and (b).

droplets to grow more slowly than others. If kinetic limitations are caused by slow dissolution, or diffusion of solute to the droplet-air interface, droplet growth will be limited by the Raoult Effect (i.e., the lowering of liquid water activity due to the presence of solute). These mechanisms would increase $S_{\text {eq }}$ in Eq. (3), leading to a reduction in the difference in water activity between the droplet and its surroundings that drives condensational growth $\left(S-S_{\mathrm{eq}}\right)$, as opposed to a true reduction in mass accommodation $(\alpha)$. Because the mechanism causing any changes in growth rate is unknown, we refer to the apparent mass accommodation coefficient $\left(\alpha_{\text {app }}\right)$ when representing droplet growth rates.

Because the composition of particles in the field is unknown, there is no way to know a priori what their critical supersaturations $\left(S_{c}\right)$ are. However, when the duration of exposure to $S$ is $30 \mathrm{~s}$ and $S$ is relatively high, the modeled $\alpha_{\text {app }}$ is relatively insensitive to $S_{c}$.For example, when condensation occurs on AS particles with $D_{\mathrm{dry}}=100 \mathrm{~nm}$ for $30 \mathrm{~s}$, the mini-

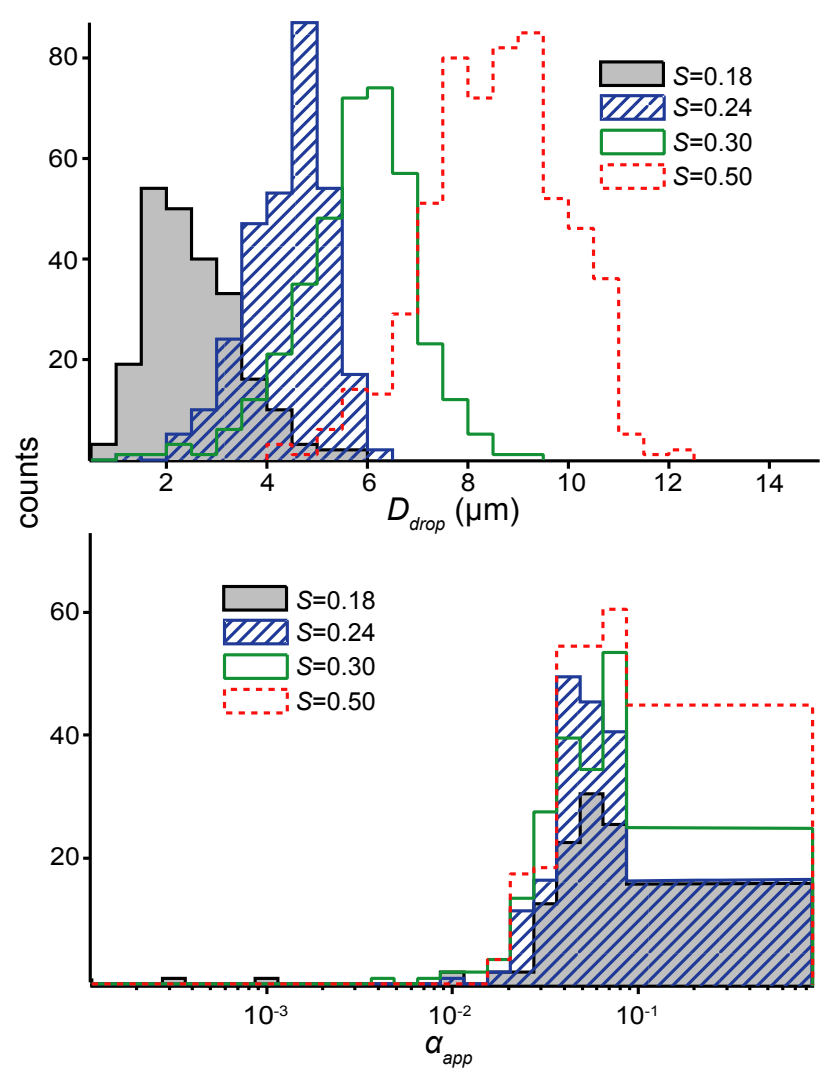

Fig. 4. $D$ and $\alpha_{\text {app }}$ distributions after 30 s of condensational growth at 4 different supersaturations on lab-generated ammonium sulfate particles.

Table 1a. Classification of individual CCN by growth kinetics.

\begin{tabular}{llll}
\hline & Very low & Low & High \\
\hline symbol & $f_{\mathrm{VL}}$ & $f_{\mathrm{L}}$ & $f_{\mathrm{H}}$ \\
\hline$\alpha$ & $<1.5 \times 10^{-3}$ & $<1.5 \times 10^{-2}$ & $>9 \times 10^{-1}$ \\
$\alpha^{\prime}$ & $<10^{-2}$ & $<10^{-1}$ & $>6$ \\
Deviation from $\alpha_{\mathrm{AS}}$ & $<-4 \sigma$ & $<-2 \sigma$ & $>1.5 \sigma$ \\
\hline
\end{tabular}

Table 1b. Classification of individual days.

\begin{tabular}{llll}
\hline Description of day & $f_{\mathrm{VL}}$ & $f_{\mathrm{L}}$ & $f_{\mathrm{H}}$ \\
\hline "Little/no kinetic inhibition" & $<1.1 \%$ & $<16 \%$ & N/A \\
"Moderate kinetic inhibition" & $<5.1 \%$ & $27-59 \%$ & N/A \\
"Strong kinetic inhibition" & $>33 \%$ & $>82 \%$ & N/A \\
"Kinetic enhancement" & N/A & N/A & $>10 \%$ \\
\hline
\end{tabular}

mum diameter detectable by the PDI, $\sim 0.5 \mu \mathrm{m}$, corresponds to $\alpha_{\text {app }}=3 \times 10^{-4}$ (Fig. 3a). When the particles are assumed to be composed of 5\% AS and $95 \%$ insoluble material, $S_{c}$ 

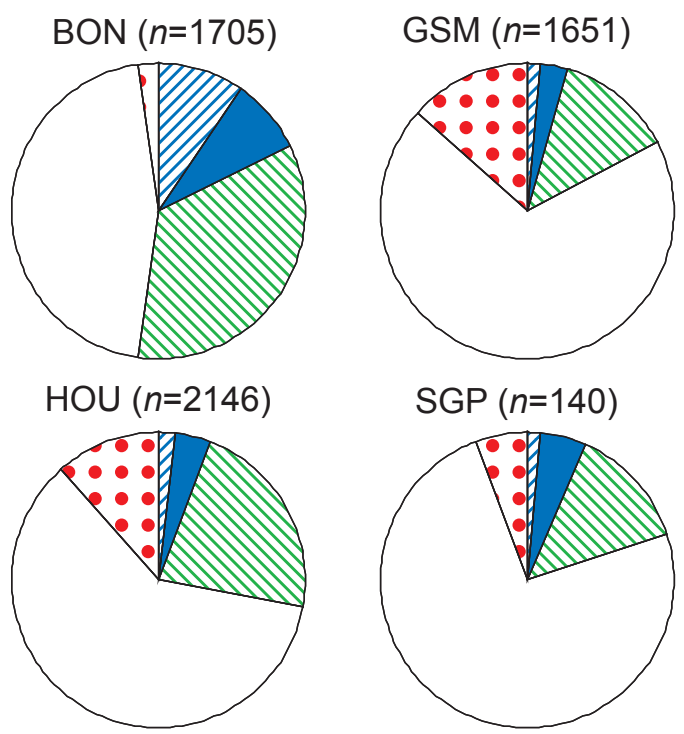

Total $(n=5642)$
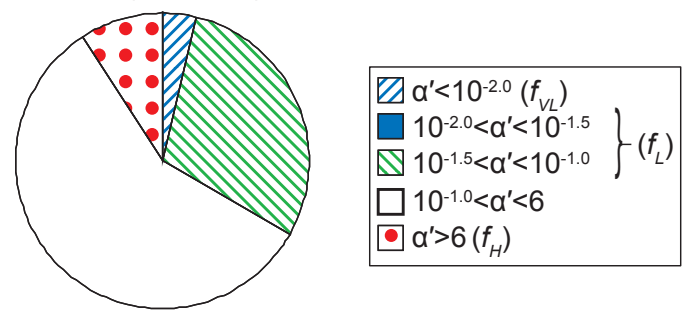

Fig. 5. Summary of $\mathrm{CCN} \alpha^{\prime}$ distributions at each site, and the total of all four sites. An $\alpha^{\prime}$ of $10^{-2.0}$ is $4 \sigma$ below the mean for ammonium sulfate $\left(\alpha_{\mathrm{app}, \mathrm{AS}}\right), \alpha^{\prime}=10^{-1.5}$ is $3 \sigma$ below $\alpha_{\mathrm{app}, \mathrm{AS}}, \alpha^{\prime}=10^{-1.0}$ is $2 \sigma$ below $\alpha_{\text {app, AS }}$, and $\alpha^{\prime}=6$ is $1.5 \sigma$ above $\alpha_{\text {app,AS }}$.

increases from $\sim 0.12 \%$ to $\sim 0.30 \%$, but at higher $S$, droplets with $\alpha_{\text {app }} \sim 10^{-3}$ are still detectable by the PDI (Fig. 3b). The difference between these two cases, i.e., the error in $\alpha_{\text {app }}$ introduced when assuming a 5\% soluble particle is fully soluble (Fig. 3c), is small ( $<0.2$ in log space) when $S$ is at least $0.1 \%$ larger than $S_{c}$ for activating droplets. This is because after activation, $S_{\text {eq }}$ drops from $S_{c}$ to $\sim 0$ as the droplet grows, and therefore, as can be seen in Eq. (3), the rate of droplet growth depends primarily on $S$, which is known, and $\alpha$. It has been previously noted that the hygroscopicity of internally mixed (soluble/insoluble) aerosols is dominated by the soluble fraction, even in small proportions (Raymond and Pandis, 2003; Bilde and Svenningsson, 2004; Broekhuizen et al., 2004). We therefore assume AS particles in the model, and assume that meaningful values of $\alpha_{\text {app }}$ will be derived as long as ambient particles with $D$ (at $\mathrm{RH} \sim 80 \%$ ) from 100 to $250 \mathrm{~nm}$ are sampled (the size range of AS particles used to determine $\alpha_{\mathrm{AS}}$ ), and measurements are made at several values of $S$. Because the hygroscopic and CCN properties of AS are relatively well known, we use it as a reference compound, and therefore all field measurements are reported as $\alpha^{\prime}$, which is $\alpha_{\text {app }}$ normalized to that of lab-generated AS par-
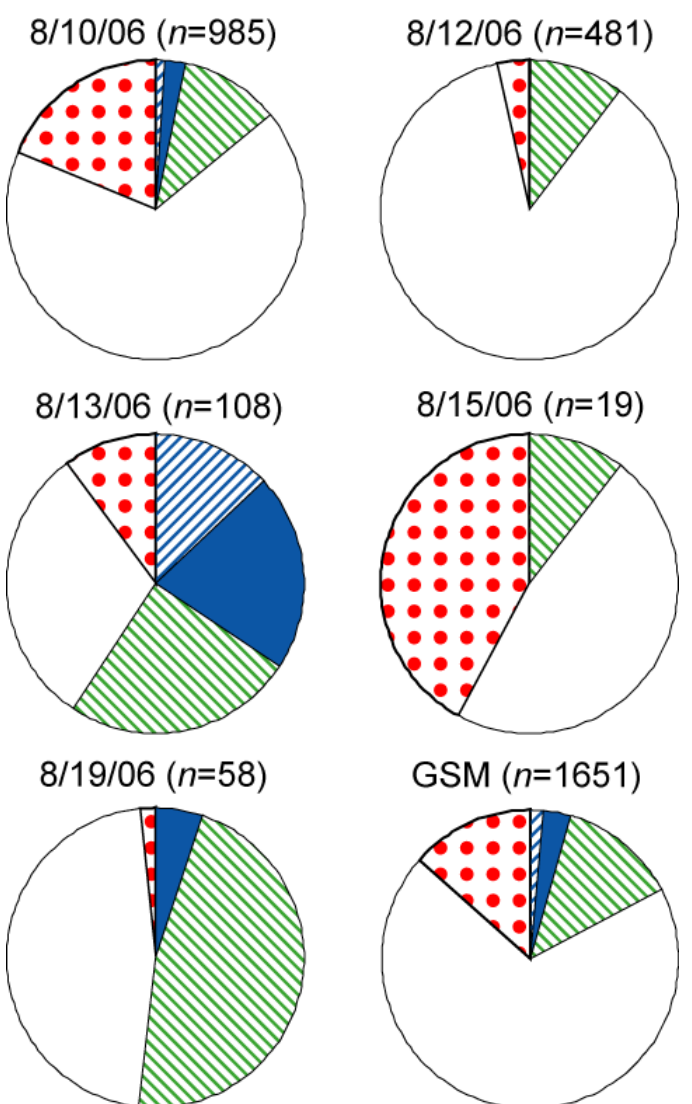

GSM $(n=1651)$
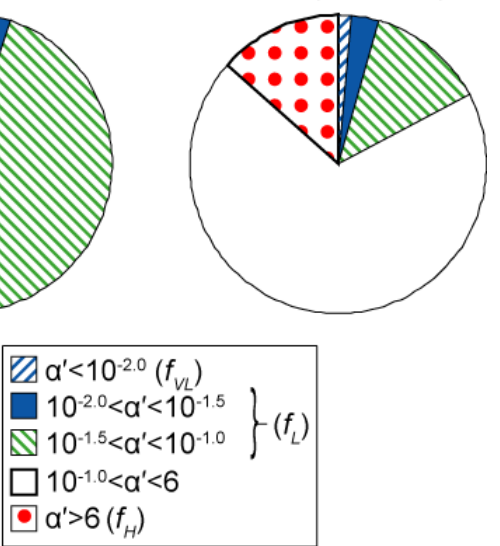

Fig. 6. Summary of $\mathrm{CCN} \alpha^{\prime}$ distributions for each day at GSM, and the total for the site. An $\alpha^{\prime}$ of $10^{-2.0}$ is $4 \sigma$ below the mean for ammonium sulfate ( $\alpha_{\text {app, AS }}$ ), $\alpha^{\prime}=10^{-1.5}$ is $3 \sigma$ below $\alpha_{\text {app, AS }}$, $\alpha^{\prime}=10^{-1.0}$ is $2 \sigma$ below $\alpha_{\text {app, AS }}$, and $\alpha^{\prime}=6$ is $1.5 \sigma$ above $\alpha$ app,AS .

ticles of the same size (at $\mathrm{RH} \sim 80 \%$ ), i.e.:

$\alpha^{\prime}=\frac{\alpha_{\text {app }}}{\alpha_{\text {app, AS }}}$.

\section{Results}

\subsection{Lab measurements of $\alpha_{\text {app }}$}

Ammonium sulfate (AS) particles were generated in the lab and sent through the same RH conditioner used in the field (producing an $\mathrm{RH} \sim 80 \%$ ) before size-selection by the DMA. $\alpha_{\text {app }}$ of these particles was determined from PDI measurements of $D$, and did not vary significantly when initial wet particle $D$ was changed from $100 \mathrm{~nm}$ to $250 \mathrm{~nm}$. Over $S$ 
Table 2. Results of all droplet growth rate measurements.

\begin{tabular}{|c|c|c|c|c|c|c|c|}
\hline Date & local time & site & $n$ & $\begin{array}{c}S \text { range } \\
(\%)\end{array}$ & $\begin{array}{l}f_{\mathrm{VL}} \\
(\%)\end{array}$ & $\begin{array}{c}f_{\mathrm{L}} \\
(\%)\end{array}$ & $\begin{array}{c}f_{\mathrm{H}} \\
(\%)\end{array}$ \\
\hline 10 Aug $2006^{\mathrm{a}, \mathrm{d}}$ & $10: 35-15: 32$ & GSM & 985 & 0.29 & 1.0 & 14 & 19 \\
\hline 12 Aug $2006^{\mathrm{a}}$ & $12: 12-19: 02$ & GSM & 481 & $0.24-0.31$ & 0.0 & 10 & 3.5 \\
\hline 13 Aug $2006^{b, d}$ & $12: 58-15: 22$ & GSM & 108 & $0.18-0.31$ & 13 & 59 & 10 \\
\hline 15 Aug $2006^{a, d}$ & $21: 27-21: 32$ & GSM & 19 & 0.47 & 0.0 & 11 & 42 \\
\hline 19 Aug $2006^{b}$ & $13: 58-14: 10$ & GSM & 58 & 0.33 & 0.0 & 52 & 1.7 \\
\hline GSM total & & & 1651 & & 1.5 & 17 & 13 \\
\hline 23 Aug $2006^{b}$ & $13: 17-15: 26$ & $\mathrm{BON}$ & 33 & 0.22 & 3.0 & 55 & 3.0 \\
\hline \multirow[t]{3}{*}{24 Aug $2006^{c}$} & $12: 24-13: 02$ & BON & 420 & $0.33-0.41$ & 0.0 & 44 & 0.0 \\
\hline & $13: 06-13: 47$ & $\mathrm{BON}$ & 202 & $0.23-0.30$ & 33 & 82 & 0.0 \\
\hline & $17: 02-17: 29$ & BON & 95 & $0.37-0.41$ & 0.0 & 14 & 3.2 \\
\hline \multirow[t]{3}{*}{25 Aug $2006^{\mathrm{c}}$} & $11: 49-12: 27$ & BON & 219 & $0.41-0.52$ & .05 & 31 & 0.5 \\
\hline & $13: 06-14: 22$ & BON & 166 & $0.23-0.34$ & 33 & 86 & 0.0 \\
\hline & $14: 38-17: 18$ & BON & 485 & $0.13-0.52$ & 8.2 & 60 & 2.3 \\
\hline 28 Aug $2006^{\mathrm{a}, \mathrm{d}}$ & $13: 40-14: 33$ & BON & 85 & $0.16-0.37$ & 0.0 & 13 & 27 \\
\hline BON total & & BON & 1705 & & 9.5 & 52 & 2.3 \\
\hline 4 Sept $2006^{\mathrm{a}, \mathrm{d}}$ & $16: 27-16: 50$ & $\mathrm{HOU}$ & 43 & $0.33-0.35$ & 0.0 & 16 & 33 \\
\hline 6 Sept $2006^{\mathrm{b}, \mathrm{d}}$ & $17: 29-19: 39$ & HOU & 176 & $0.30-0.44$ & 5.1 & 27 & 25 \\
\hline \multirow[t]{2}{*}{7 Sept $2006^{a, d}$} & 11:47-12:09 & HOU & 1023 & $0.34-0.56$ & 2.3 & 43 & 0.0 \\
\hline & $16: 58-17: 40$ & $\mathrm{HOU}$ & 274 & $0.35-0.49$ & 0.7 & 14 & 31 \\
\hline 8 Sept $2006^{a, d}$ & $11: 24-11: 32$ & HOU & 164 & 0.63 & 0.0 & 1.2 & 18 \\
\hline 11 Sept $2006^{\mathrm{a}, \mathrm{d}}$ & $12: 23-21: 17$ & HOU & 466 & $0.28-0.63$ & 1.1 & 15 & 17 \\
\hline HOU total & & $\mathrm{HOU}$ & 2146 & & 1.8 & 28 & 12 \\
\hline 16 Sept $2006^{b}$ & $16: 01-16: 36$ & SGP & 97 & $0.34-0.63$ & 2.1 & 28 & 8.2 \\
\hline 22 Sept $2006^{a}$ & $14: 39-14: 57$ & SGP & 43 & $0.41-0.63$ & 0.0 & 2.3 & 0.0 \\
\hline SGP total & & SGP & 140 & & 1.4 & 20 & 5.7 \\
\hline total (all sites) & & & 5642 & & 4.0 & 32 & 9.2 \\
\hline
\end{tabular}

a little/no kinetic inhibitions to condensational growth

$\mathrm{b}$ moderate kinetic inhibition

c strong kinetic inhibition

${ }^{d}$ kinetic enhancement to growth

ranging from $0.18 \%$ to $0.50 \%$ (roughly corresponding to the range of $D$ detectable by PDI), $\alpha_{\text {app,AS }}$ was $10^{-0.82 \pm 0.52}$, or $0.15(0.045-0.51)$ (Fig. 4). The uncertainty quoted is $1 \sigma$ (in log space). Therefore, according to Eq. (5), we report all field measurements of $\alpha_{\text {app }}$ normalized to AS as $\alpha^{\prime}=\alpha_{\text {app }} / 0.15$. Furthermore, because they are significantly different from AS droplets, we refer to CCN with $\alpha^{\prime}<10^{-1}, \alpha^{\prime}<10^{-2}$, and $\alpha^{\prime}>6$ as "low- $\alpha^{\prime \prime}$," "very low- $\alpha^{\prime \prime}$," and "high- $\alpha^{\prime \prime}, \mathrm{CCN}$, respectively, and report the fraction of CCN that were low- $\alpha^{\prime}$ $\left(f_{\mathrm{L}}\right)$, very low- $\alpha^{\prime}\left(f_{\mathrm{VL}}\right)$, and high- $\alpha^{\prime}\left(f_{\mathrm{H}}\right)$ (see Table 1$)$.

\subsection{Field measurements of $\alpha^{\prime}$}

The growth rate of droplets was measured as described above on a total of 16 days between 10 August and 22 September, 2006 (see Table 2 for a summary of all measurements). On days when different time periods yielded distinct results, the periods are listed separately. Overall, $\alpha^{\prime}$ for a majority of droplets $(59 \%)$ was between 0.1 and 6 (i.e., $\alpha_{\text {app }}$ between $-2 \sigma$ and $1 \sigma$ relative to droplets formed on AS particles), but among the sites this fraction of $\mathrm{CCN}$ with similar growth rates to AS ranged from $46 \%$ at BON to $69 \%$ at GSM (Fig. 5). GSM was characterized by relatively large day-today variability in $\alpha^{\prime}$ distributions (Fig. 6). Daily variability in $\alpha^{\prime}$ distributions was also relatively high at $\mathrm{BON}$, which had the highest fraction of low- $\alpha^{\prime} \mathrm{CCN}\left(f_{\mathrm{L}}=52 \%\right)$ among the sites (Fig. 7). HOU had less daily variability than GSM and $\mathrm{BON}$, and was the only site which had high- $\alpha^{\prime} \mathrm{CCN}$ each day (Fig. 8). Less data was available from SGP than the other sites, but CCN from this site did have similar growth kinetics to those from $\mathrm{HOU}$, although no high- $\alpha^{\prime} \mathrm{CCN}$ were detected (Fig. 9). For individual time periods at all sites, $f_{\mathrm{L}}$ and $f_{\mathrm{VL}}$ ranged from 0 to $89 \%$ and 0 to $33 \%$, respectively, and $f_{\mathrm{H}}$ ranged from 0 to $42 \%$. 

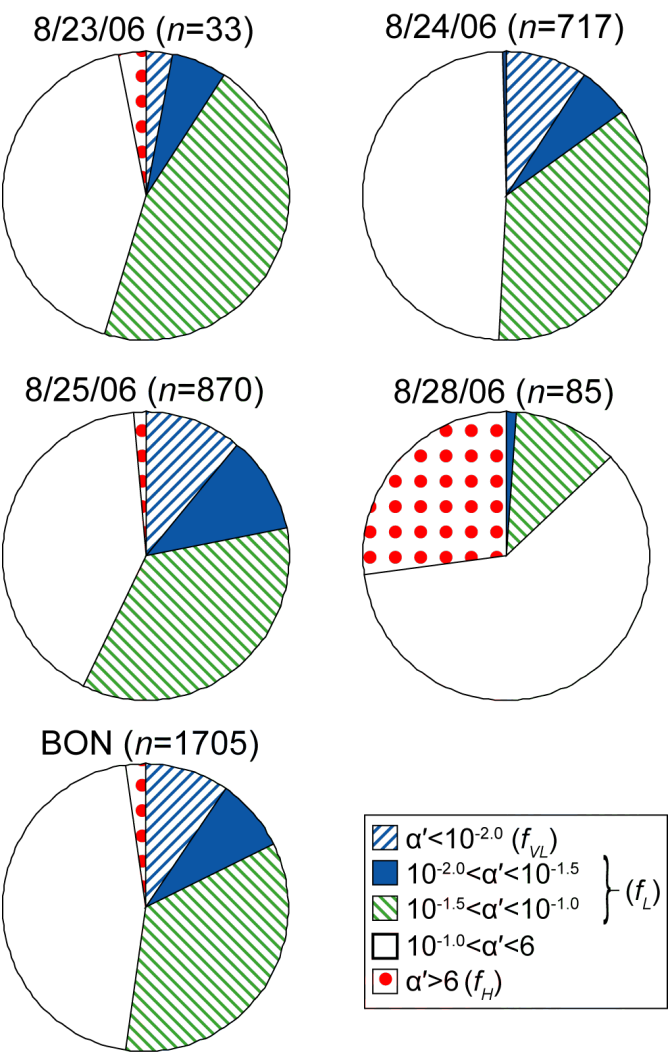

Fig. 7. Summary of $\mathrm{CCN} \alpha^{\prime}$ distributions for each day at BON, and the total from the site. An $\alpha^{\prime}$ of $10^{-2.0}$ is $4 \sigma$ below the mean for ammonium sulfate ( $\alpha_{\text {app, AS }}$ ), $\alpha^{\prime}=10^{-1.5}$ is $3 \sigma$ below $\alpha_{\text {app, AS }}$, $\alpha^{\prime}=10^{-1.0}$ is $2 \sigma$ below $\alpha_{\text {app, AS }}$, and $\alpha^{\prime}=6$ is $1.5 \sigma$ above $\alpha_{\text {app, AS }}$.

Among the 16 days, we identify those with either (a) little/no, (b) moderate, or (c) strong kinetic inhibition to condensational growth, as well as those with (d) kinetic enhancement to growth (see Table 1). Seven of the 16 days had little/no inhibition $\left(f_{\mathrm{VL}}<1.1 \%\right.$ and $\left.f_{\mathrm{L}}<16 \%\right), 7$ days had at least one period with moderate inhibition $\left(f_{\mathrm{VL}}<5.1 \%\right.$ and $27 \%<f_{\mathrm{L}}<59 \%$ ), and 2 days had at least one period with strong inhibition $\left(f_{\mathrm{VL}}>33 \%\right.$ and $\left.f_{\mathrm{L}}>82 \%\right)$. Also, we detected $\mathrm{CCN}$ with enhanced kinetic growth $\left(10 \%<f_{\mathrm{H}}<42 \%\right)$ on 9 out of 16 days. All 4 sites experienced at least one day with moderate or strong inhibition to condensational growth relative to AS, including one out of 2 days at SGP and 2 out of 5 days at HOU, although relatively few very low- $\alpha^{\prime}$ $\mathrm{CCN}\left(f_{\mathrm{VL}}=1.4 \%\right)$ were detected at SGP. Moderate inhibition was observed on 2 out of 5 days at the polluted regional site (GSM), and 2 out of 4 days at one continental background site (BON) had strong inhibition to growth. On both days with strong inhibition, kinetic limitations peaked around local noon and decreased later in the day (Fig. 10). A decrease in $f_{\mathrm{L}}$ later in the day was also seen at HOU (Fig. 11). Kinetic enhancement to condensational growth (relative to AS)
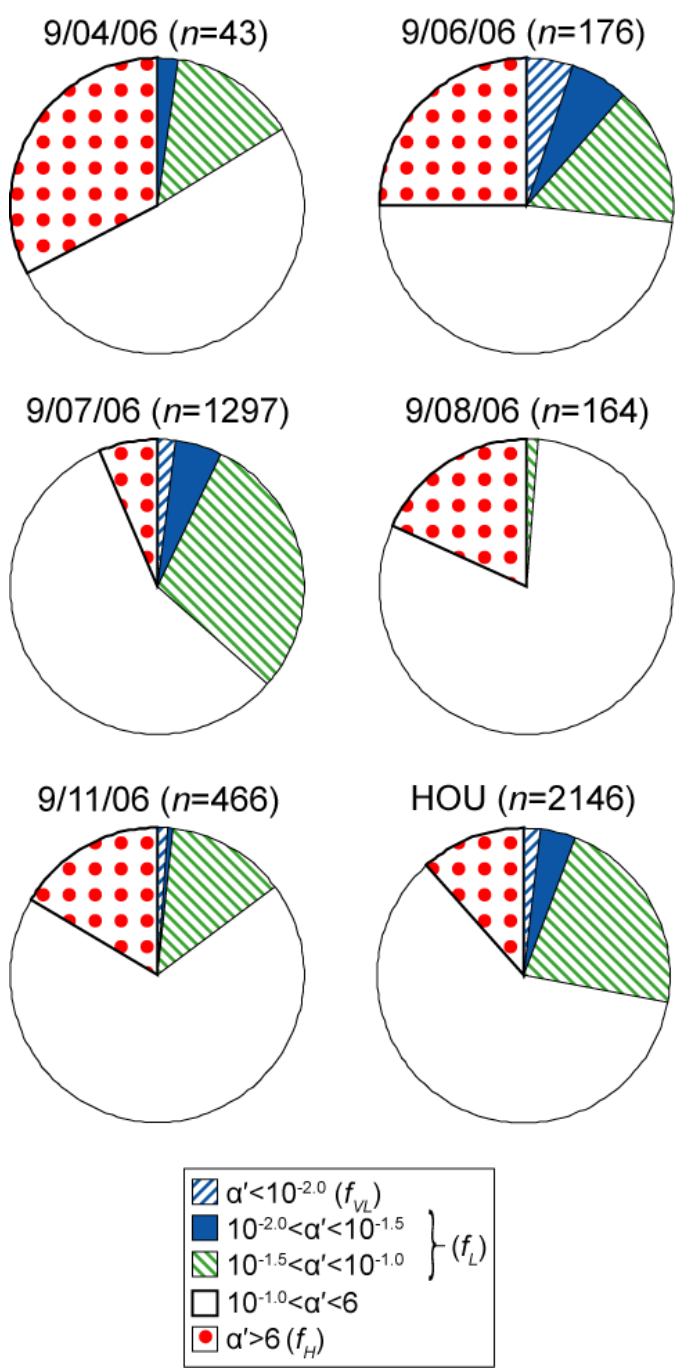

Fig. 8. Summary of $\mathrm{CCN} \alpha^{\prime}$ distributions for each day at HOU, and the total from the site. An $\alpha^{\prime}$ of $10^{-2.0}$ is $4 \sigma$ below the mean for ammonium sulfate $\left(\alpha_{\mathrm{app}, \mathrm{AS}}\right), \alpha^{\prime}=10^{-1.5}$ is $3 \sigma$ below $\alpha_{\mathrm{app}, \mathrm{AS}}$, $\alpha^{\prime}=10^{-1.0}$ is $2 \sigma$ below $\alpha_{\text {app, AS }}$, and $\alpha^{\prime}=6$ is $1.5 \sigma$ above $\alpha_{\text {app, AS }}$.

was also observed, but typically in a much smaller fraction of $\mathrm{CCN}$ than those with inhibited growth. The polluted regional site (GSM) had the highest fraction of high- $\alpha^{\prime} \mathrm{CCN}$ $\left(f_{\mathrm{H}}=13 \%\right)$, followed by HOU (12\%), SGP $(5.7 \%)$, and BON $(2.3 \%)$.

\section{Discussion and conclusions}

To potentially explain the observed daily variability in droplet growth rates, we compared back trajectories for the days during which measurements were taken at BON and GSM (Figs. 12 and 13, respectively). According to these analyses, air masses descending from $>1000 \mathrm{~m}$ above ground level arrived both days at BON that had highest- 

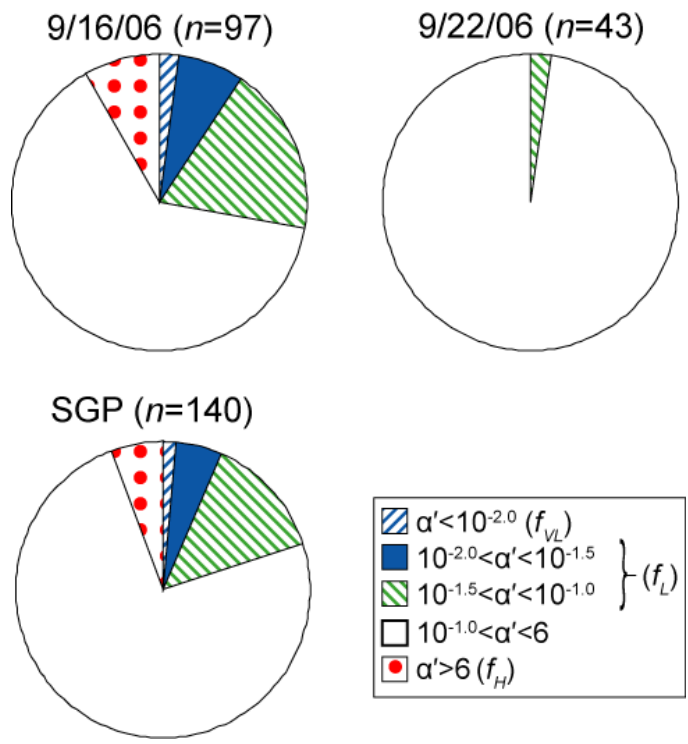

Fig. 9. Summary of $\mathrm{CCN} \alpha^{\prime}$ distributions for both days at SGP, and the total from the site. An $\alpha^{\prime}$ of $10^{-2.0}$ is $4 \sigma$ below the mean for ammonium sulfate $\left(\alpha_{\mathrm{app}, \mathrm{AS}}\right), \alpha^{\prime}=10^{-1.5}$ is $3 \sigma$ below $\alpha_{\text {app, AS }}$, $\alpha^{\prime}=10^{-1.0}$ is $2 \sigma$ below $\alpha_{\text {app, AS }}$, and $\alpha^{\prime}=6$ is $1.5 \sigma$ above $\alpha_{\text {app, AS }}$.

observed low- $\alpha^{\prime} \mathrm{CCN}$ (Fig. 12b, c), but were absent on other days (Fig. 12a, d). A similar pattern was seen at GSM: air from aloft ( $>1000 \mathrm{~m}$ elevation) was arriving throughout the one day in which there was moderate inhibition to condensational growth (Fig. 13c), whereas on other days descending air was either absent or intermittent (Fig. 13a, b, d). If air arriving from aloft contains accumulation mode aerosols that have survived one or more cloud cycles, and these cycles selectively remove high- $\alpha^{\prime} \mathrm{CCN}$ via wet deposition, low- $\alpha^{\prime}$ $\mathrm{CCN}$ should be more prevalent in air arriving from aloft. Novakov et al. (1997) observed an increase in aerosol carbon mass fraction with altitude in the eastern United States. Similarly, Andrews et al. (2004) observed a slight decrease in single-scatter albedo with altitude above SGP in data collected over two years, which was likely due to an increase in carbonaceous content. Other studies have confirmed the abundance of organic matter aerosols in the free troposphere (e.g., Murphy et al., 1998; Heald et al., 2005). Most potential mechanisms of kinetic limitations to droplet growth likely involve organic matter (e.g., slowly-dissolving or film-forming compounds), and therefore the preponderance of organic material in free tropospheric aerosols is consistent with our observations that low- $\alpha^{\prime} \mathrm{CCN}$ seemed to be more prevalent in air masses arriving from aloft.

Kinetic inhibitions to condensational growth were strong on two days at BON, and although there was less daily variability at HOU, one period during 7 Sept. had more low- $\alpha^{\prime}$ $\left(f_{\mathrm{L}}=43 \%\right)$ than all other HOU times $\left(f_{\mathrm{L}}<27 \%\right)$. On each of these three days, kinetic limitations peaked around noon,

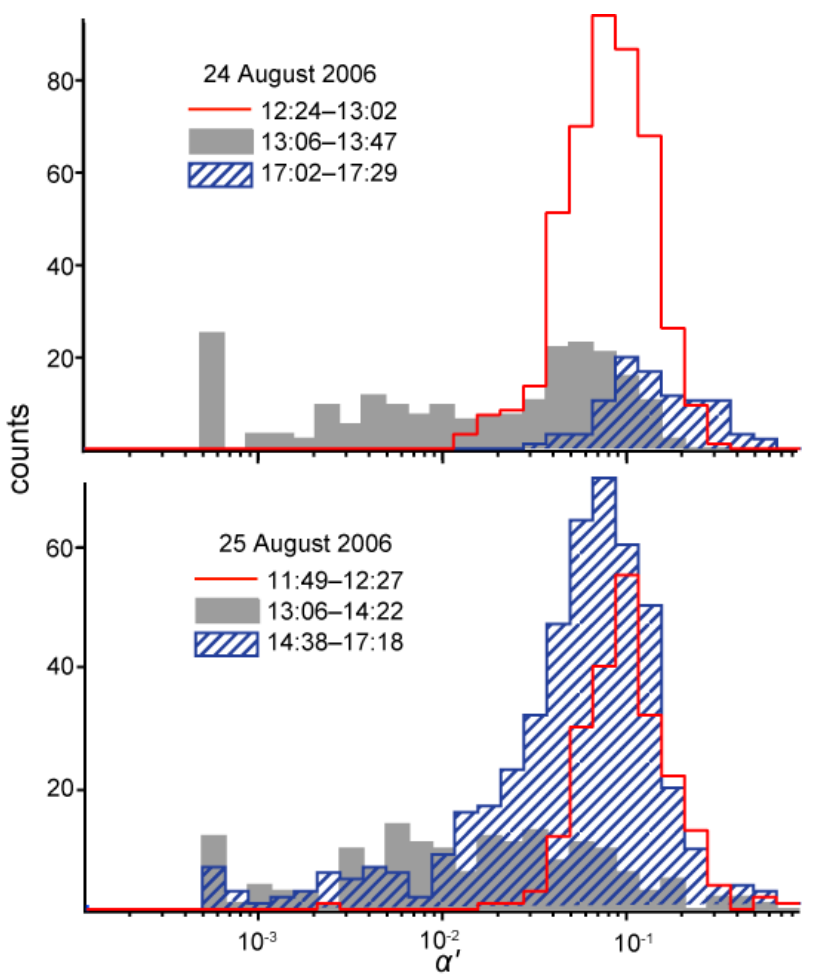

Fig. 10. $\alpha^{\prime}$ distributions for various periods on the two days with strong inhibitions to condensational growth (both at BON).

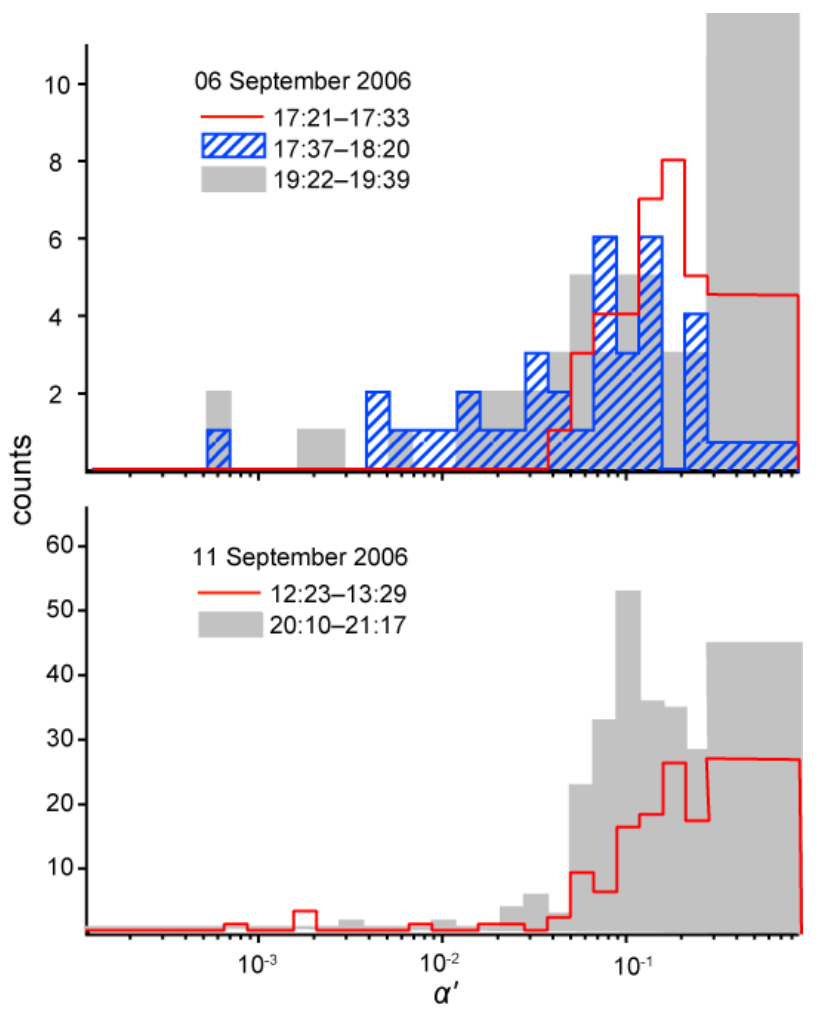

Fig. 11. $\alpha^{\prime}$ distributions for various periods on two days from HOU. 


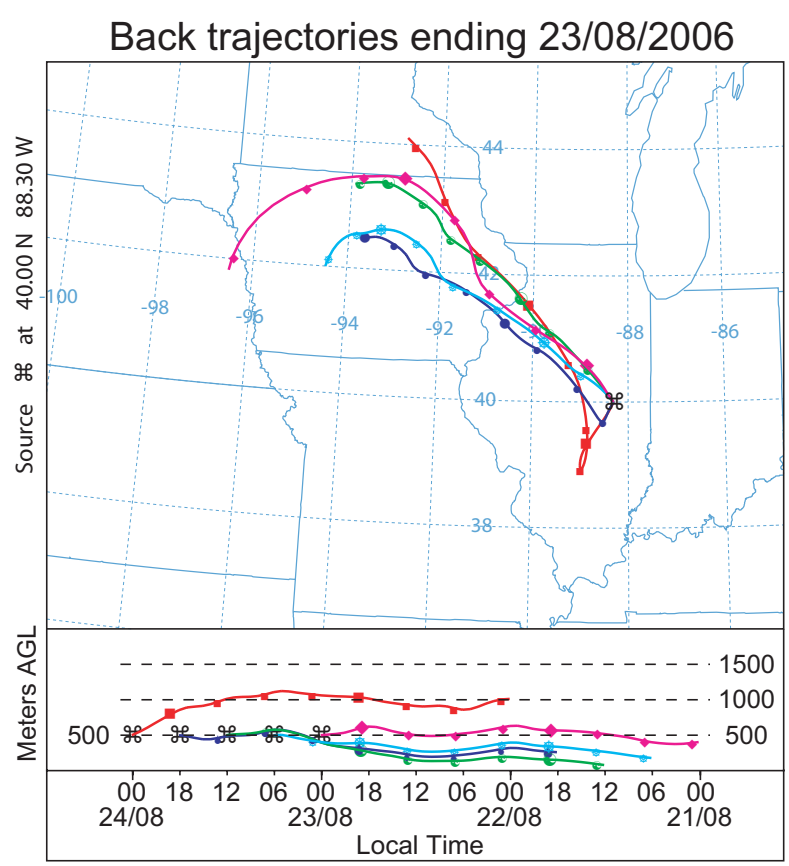

(a)

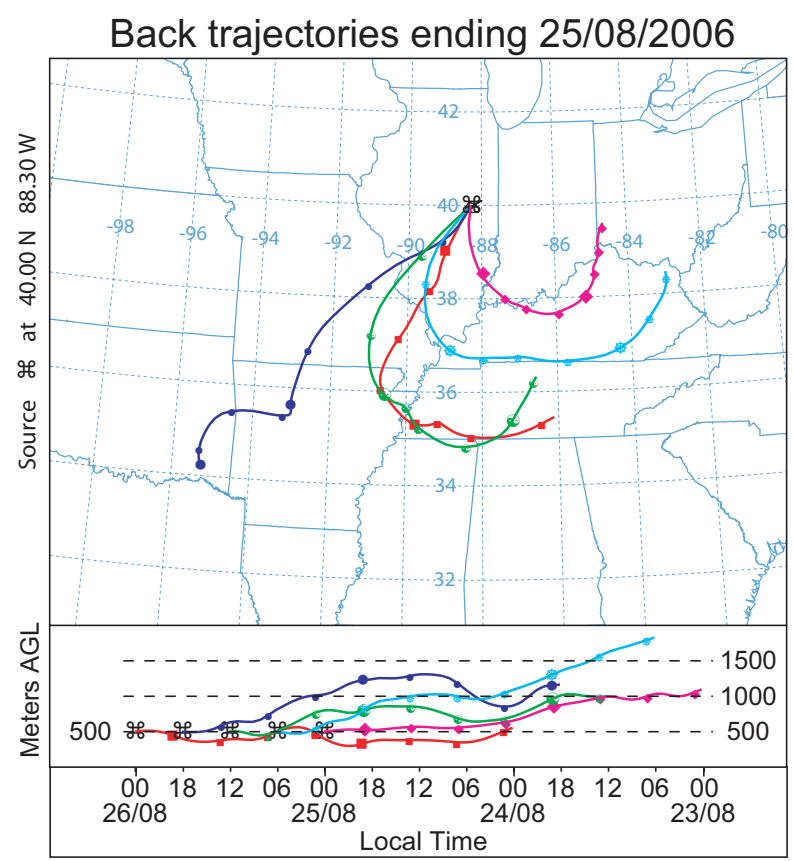

(c)

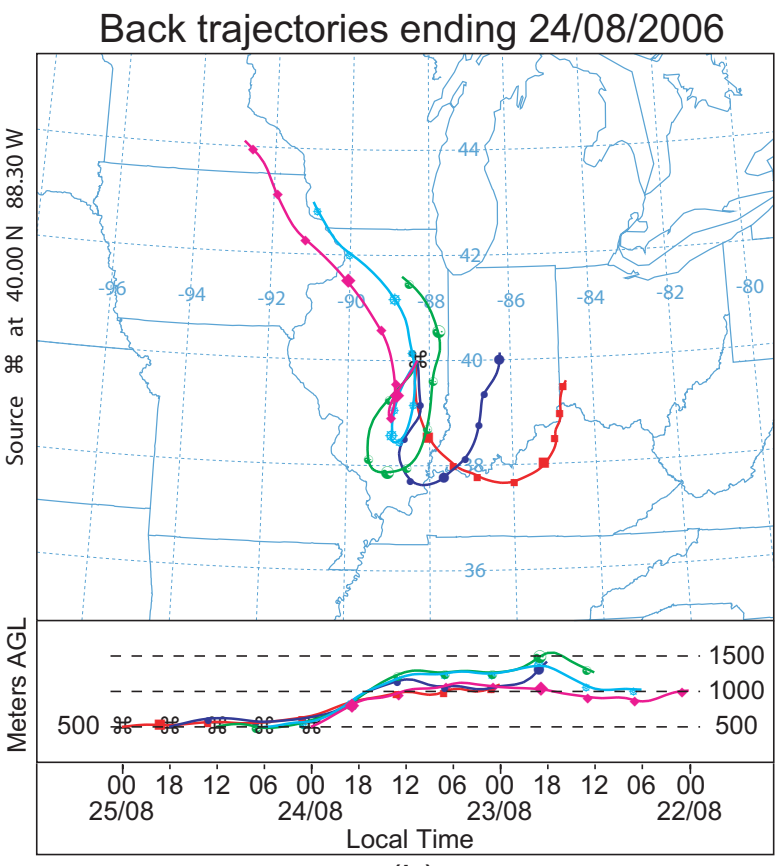

(b)

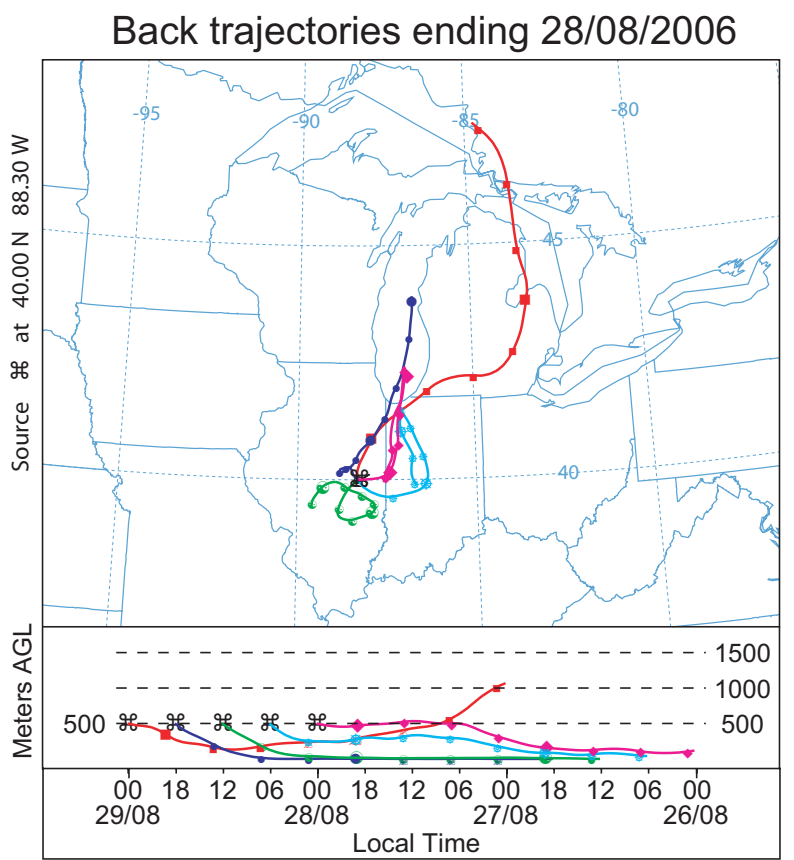

(d)

Fig. 12. NOAA HYSPLIT back trajectories ending at the BON site, ending on (a) 23/08/2006, (b) 24/08/2006, (c) 25/08/2006, and (d) 28/08/2006.

and decreased later in the day. It is possible that photochemical aging of the ambient aerosol on those days caused the particles to become more oxidized and therefore more soluble, and that this is the reason for the consistent decrease in low- $\alpha^{\prime}$ droplets throughout the afternoon. Much more data would be required, however, to rigorously test this hypothesis. We also observed $\mathrm{CCN}$ that grew more rapidly than lab-generated AS. One possible explanation for this is the presence of surface-active substances that might act to lower $S_{\text {eq }}$, and thus increase the difference between $S$ and $S_{\text {eq }}$ that 


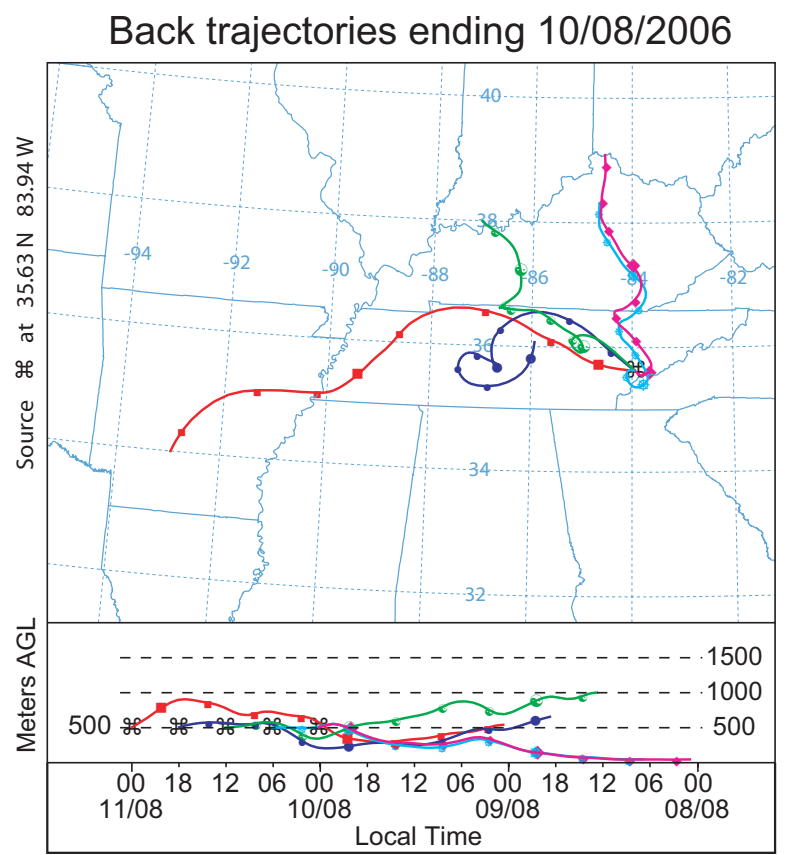

(a)

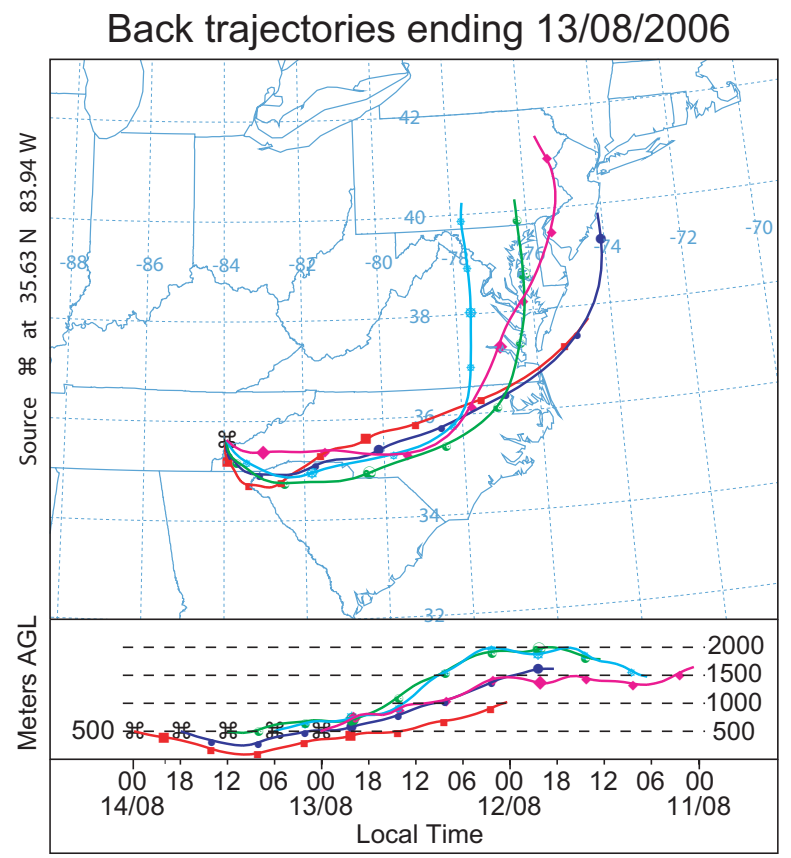

(c)

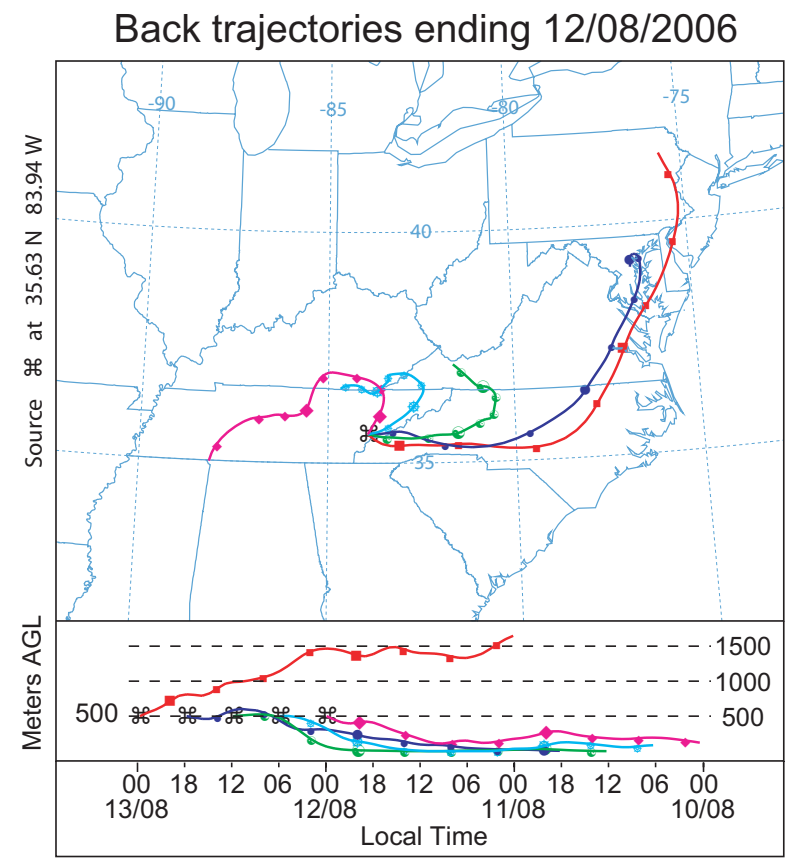

(b)

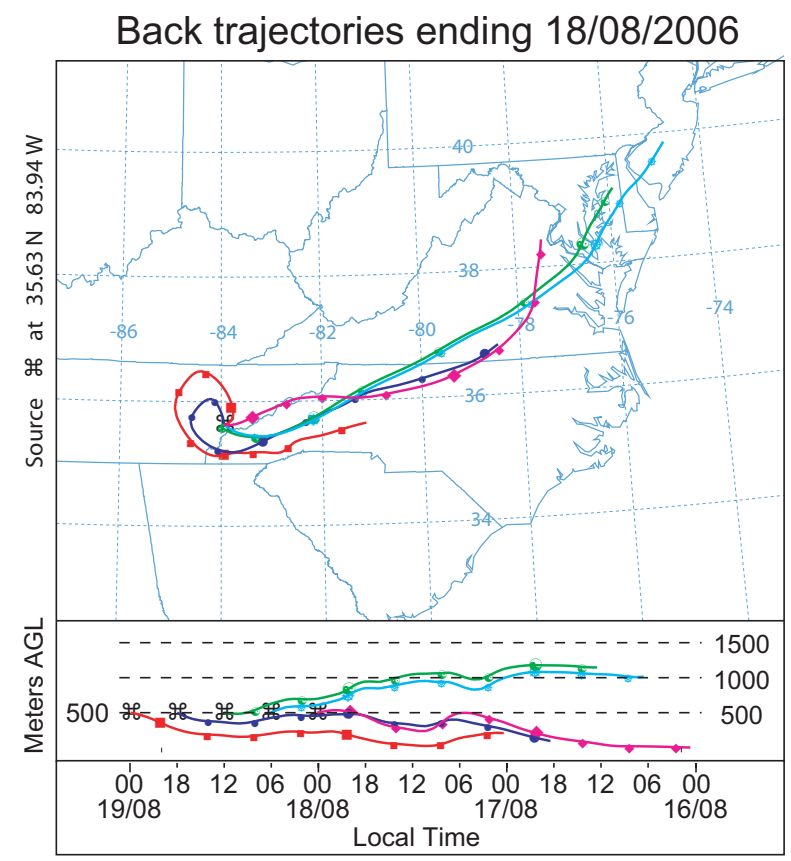

(d)

Fig. 13. NOAA HYSPLIT back trajectories ending at the GSM site, ending on (a) 10/08/2006, (b) 12/08/2006, (c) 13/08/2006, and (d) $18 / 08 / 2006$.

drives condensational growth, i.e., the numerator on the right side of Eq. (3). Additionally, these high- $\alpha^{\prime} \mathrm{CCN}$ might be sea salt particles, which should grow more rapidly than AS particles because there are more ions in a $\mathrm{NaCl}$ particle of a given size. This could explain why high- $\alpha^{\prime} \mathrm{CCN}$ were observed each day in HOU. Again, more data would be required, including compositional data, before either mechanism for increased growth rates could be verified. 
These results suggest that aerosols containing $\mathrm{CCN}$ with $\alpha_{\text {app }}$ significantly lower than that observed for laboratorygenerated AS are fairly common in the atmosphere, as they were observed on 8 out of 16 days at four different field sites. Kinetic limitations of this magnitude could keep these particles from being activated under atmospherically relevant timescales of exposure to water vapor supersaturation (i.e., $\sim 30$ s). These particles could be partly responsible for overprediction of $\mathrm{CCN}$ concentrations in previous closure experiments, and could also lead to broadening of cloud droplet spectra that might diminish the affect of increased aerosol concentrations on cloud radiative properties (Liu and Daum, 2002). Low- $\alpha^{\prime}$ CCN might also have a longer atmospheric lifetime than other particles due to less efficient removal by wet deposition. Less efficient removal could, in fact, explain why slowly-growing particles seemed to be present in air masses arriving from aloft, if a portion of the particles in these masses had already been subject to one or more cloud cycles with at least some precipitation.

Acknowledgements. The authors would like to acknowledge primary funding from the NASA Radiation Sciences Program, as well as a National Science Foundation Graduate Research Fellowship, and the Houston Advanced Research Center for funding the TexAQS II Radical and Aerosol Measurement Project site. Furthermore, the authors would like to thank the following people for logistical help in the field: J. Renfro of Great Smokey Mountain National Park, D. Gay and M. Snider of the Illinois State Water Survey, B. Rappenglück and B. Lefer of the University of Houston, and B. Orr and D. Nelson of the Atmospheric Radiation Program Southern Great Plains facility. The authors would also like to thank J. Ogren and A. Jefferson of the NOAA Global Monitoring Division for lending various instruments that were used in the field. Finally, J. Ruehl, J. Small, D. Rossiter, R. Ruehl, and L. Ziemba provided much appreciated assistance in the field.

Edited by: U. Lohmann

\section{References}

Andrews, E., Sheridan, P. J., Ogren, J. A., and Ferrare, F.: In situ aerosol profiles over the Southern Great Plains cloud and radiation test bed site: 1. Aerosol optical properties, J. Geophys. Res., 109, D06208, doi:10.1029/2003JD004025, 2004.

Bachalo, W. D.: A method for measuring the size and velocity of spheres by dual beam light scatter interferometry, Appl. Optics, 19, 363-370, 1980.

Bachalo, W. D. and Houser, M. J.: Phase Doppler spray analyzer for simultaneous measurements of drop size and velocity distributions, Opt. Eng., 23, 583-590, 1984.

Bachalo, W. D. and Sankar, S. V.: Phase Doppler particle analyzer, in: Handbook of Fluid Dynamics, edited by: Johnson, R. W., CRC Press, 1996.

Bilde, M. and Svenningsson, B.: CCN activation of slightly soluble organics: the importance of small amounts of inorganic salt and particle phase, Tellus B, 56, 128-134, 2004.

Broekhuizen, K., Kumar, P. P., and Abbatt, J. P. D.: Partially soluble organics as cloud condensatgion nuclei: Role of trace solu- ble and surface active species, Geophys. Res. Lett., 31, L01107, doi:10.1029/2003GL018203, 2004.

Cantrell, W., Shaw, G., Cass, G. R., Chowdhury, Z., Hughes, L. S., Prather, K. A., Guazzotti, S. A., and Coffee, K. R.: Closure between aerosol particles and cloud condensation nuclei at Kaashidhoo Climate Observatory, J. Geophys. Res., 106, 28711-28 718, 2001.

Chuang, P. Y., Charlson, R. J., and Seinfeld, J. H.: Kinetic limitations on droplet formation in clouds, Nature, 390, 594-596, 1997.

Chuang, P. Y., Collins, D. R., Pawlowska, H., Snider, J. R., Jonsson, H. H., Brenguier, J.-L. , Flagan, R. C., and Seinfeld, J. H.: CCN measurements during ACE-2 and their relationship to cloud microphysical properties, Tellus, 52B, 843-867, 2000.

Chuang, P. Y.: Measurement of the timescale of hygroscopic growth for atmospheric aerosols, J. Geophys. Res., 108, 4282, doi:10.1029/2002JD002757, 2003.

Conant, W. C., VanReken, T. M., Rissman, T. A., Varutbangkul, V., Jonsson, H. H., Nenes, A., Jimenez, J. L., Delia, A. E., Bahreini, R. Roberts, G. C., Flagan, R. C., and Seinfeld, J. H.: Aerosolcloud drop concentration closure in warm cumulus, J. Geophys. Res., 109, D13204, doi:10.1029/2003JD004324, 2004.

Covert, D. S., Gras, J. L., Wiedensohler, A., and Stratmann, F.: Comparison of directly measured $\mathrm{CCN}$ with $\mathrm{CCN}$ modeled from the number-size distribution in the marine boundary layer during ACE 1 at Cape Grim, Tasmania, J. Geophys. Res., 103, $16597-$ 16608, 1998.

Ervens, B., Cubison, M., Andrews, E., Feingold, G., Ogren, J. A., Jimenez, J. L., DeCarlo, P., and Nenes, A.: Prediction of cloud condensation nucleus number concentration using measurements of aerosol size distributions and composition and light scattering enhancement due to humidity, J. Geophys. Res., 112, D10S32, doi:10.1029/2006JD007426, 2007.

Facchini, M. C., Mircea, M., Fuzzi, S., and Charlson, R. J.: Cloud albedo enhancement by surface-active organic solutes in growing droplets, Nature, 401, 257-259, 1999.

Feingold, G. and Chuang, P. Y.: Analysis of the influence of filmforming compounds on droplet growth: Implications for cloud microphysical processes and climate, J. Atmos. Sci., 59, 20062018, 2002.

Hallberg, A., Wobrock, W., Flossmann, A. I., Bower, K. N., Noone, K. J., Wiedensohler, A., Hansson, H.-C., Wendisch, M., Berner, A., Kruisz, C., Laj, P., Facchini, M. C., Fuzzi, S., and Arends, B. G.: Microphysics of clouds: Model vs. measurements, Atmos. Environ., 31, 2453-2310, 1997.

Heald, C. L., Jacob, D. J., Park, R. J., Russell, L. M., Huebert, B. J., Seinfeld, J. H., Liao, H., and Weber, R. J.: A large organic aerosol source in the free troposphere missing from current models, Geophys. Res. Lett., 32, L18809, doi:10.1029/2005GL023831, 2005.

IPCC: Contribution of Working Group I to the Fourth Assessment Report of the Intergovernmental Panel on Climate Change, edited by: Solomon, S., Qin, D., Manning, M., et al., Cambridge University Press, 2007.

Iziomon, M. G. and Lohmann, U.: Characteristics and direct radiative effect of mid-latitude continental aerosols: the ARM case, Atmos. Chem. Phys., 3, 1903-1917, 2003, http://www.atmos-chem-phys.net/3/1903/2003/.

Kim, E., Hopke, P. K., Kenski, D. M., and Koerber, M.: Sources 
of fine particles in a rural midwestern U.S. area, Environ. Sci. Technol., 39, 4953-4960, 2005.

Köhler, H.: The nucleus in and the growth of hygroscopic droplets, T. Faraday Soc., 32, 1152-1161, 1936.

Kulmala, M., Laaksonen, A., Korhonen, P., Vesala, T., Ahonen, T., and Barrett, J.: The effect of atmospheric nitric acid vapor on cloud condensation nucleus activation, J. Geophys. Res., 98, 22 949-22 958, 1993.

Laaksonen, A., Vesala, T., Kulmala, M., Winkler, P. M., and Wagner, P. E.: Commentary on cloud modelling and the mass accommodation coefficient of water, Atmos. Chem. Phys., 5, 461-464, 2005 , http://www.atmos-chem-phys.net/5/461/2005/.

Liu, Y. and Daum, P. H.: Anthopogenic aerosols: Indirect warming effect from dispersion forcing, Nature, 419, 580-581, 2002.

Medina, J., Nenes, A., Sotiropoulou, R.-E. P., Cottrell, L. D., Ziemba, L. D., Beckman, P. J., and Griffin, R. J.: Cloud condensation nuclei closure during the International Consortium for Atmospheric Research on Transport and Transformation 2004 campaign: Effects of size-resolved composition, J. Geophys. Res., 112, D10S31, doi:10.1029/2006JD007588, 2007.

Murphy, D. M., Thomson, D. S., and Mahoney, M. J.: In situ measurements of organics, meteoric material, mercury, and other elements in aerosols at 5 to 19 kilometers, Science, 282, 1664-1669, 1998.

Nenes, A., Charlson, R. J., Facchini, M. C., Kulmala, M., Laaksonen, A., and Seinfeld, J. H.: Can chemical effects on cloud droplet number rival the first indirect effect?, Geophys. Res. Lett., 29, 1848, doi:10.1029/2002GL015295, 2002.

Novakov, T. and Penner, J. E.: Large contribution of organic aerosols to cloud-condensation-nuclei concentrations, Nature, 365, 823-826, 1993.

Novakov, T., Hegg, D. A., and V. Hobbs, P. V.: Airborne measurements of carbonaceous aerosols on the East Coast of the United States, J. Geophys. Res., 102, 30 023-30 030, 1997.

Raymond, T. M. and Pandis, S. N.: Formation of cloud droplets by multicomponent organic particles, J. Geophys. Res., 108, 4469, doi:10.1029/2003JD003503, 2003.

Rissler, J., Swietlicki, E., Zhou, J., Roberts, G., Andreae, M. O., Gatti, L. V., and Artaxo, P.: Physical properties of the submicrometer aerosol over the Amazon rain forest during the wetto-dry season transition - comparison of modeled and measured CCN concentrations, Atmos. Chem. Phys., 4, 2119-2143, 2004, http://www.atmos-chem-phys.net/4/2119/2004/.

Roberts, G. C. and Nenes, A.: A continuous-flow streamwise thermal-gradient $\mathrm{CCN}$ chamber for atmospheric measurements, Aerosol Sci. Tech., 39, 206-221, 2005.
Rubel, G. O. and Gentry, J. W.: Measurement of the kinetics of solution droplets in the presence of adsorbed monolayers: Determination of water accommodation coefficients, J. Phys. Chem.U.S., 88, 3142-3148, 1984.

Russell, M., Allen, D., Collins, D., and Fraser, M.: Daily, seasonal, and spatial trends in $\mathrm{PM}_{2.5}$ mass and composition in southeast Texas, Aerosol Sci. Tech., 38, 14-26, 2004.

Sankar, S. V., Weber, B. J., Kamemoto, D. Y., and Bachalo, W. D.: Sizing fine particles with the phase Doppler interferometric technique, Appl. Optics, 30, 4914-4920, 1991.

Seaver, M., Peele, J. R., Manuccia, T. J., Rubel, G. O., and Ritchie, G.: Evaporation kinetics of ventilated waterdrops coated with octadecanol monolayers, J. Phys. Chem.-U.S., 96, 6389-6394, 1992.

Shaw, R. A. and D. Lamb: Experimental determination of the thermal accommodation and condensation coefficients of water, J. Chem. Phys., 111, $10659-10663,1999$.

Snider, J. R. and Brenguier, J.-L.: Cloud condensation nuclei and cloud droplet measurements during ACE-2, Tellus B, 828-842, 2000.

Snider, J. R., Guibert, S., Brenguier, J.-L., and Putaud, J.-P.: Aerosol activation in marine stratocumulus clouds: 2. Köhler and parcel theory closure studies, J. Geophys. Res., 108, 8629, doi:10.1029/2002JD002692, 2003.

Stroud, C. A., Nenes, A., Jimenez, J. L., DeCarlo, P. F, Huffman, J. A., Bruintjes, R., Nemitz, E., Delia, A. E., Toohey, D. W., Guenther, A. B., and Nandi, S.: Cloud activating properties of aerosol observed during CELTIC, J. Atmos. Sci., 64, 441-459, 2007.

Tanner, R. L., Parkhurst, W. J., Valente, M. L., and Phillips, W. D.: Regional composition of $\mathrm{PM}_{2.5}$ aerosols measured at urban, rural, and "background" sites in the Tennessee valley, Atmos. Environ., 38, 3143-3153, 2004.

VanReken, T. M., Rissman, T. A., Roberts, G. C., Varutbangkul, V., Jonsson, H. H., Flagan, R. C., and Seinfeld, J. H.: Toward aerosol/cloud condensation nuclei (CCN) closure during CRYSTAL-FACE, J. Geophys. Res., 108, 4633, doi:10.1029/2003JD003582, 2003.

Zhou, J. C., Swietlicki, E., Berg, O. H., Aalto, P. P., Hameri, K., Nilsson, E. D., and Leck, C. Hygroscopic properties of aerosol particles over the central Arctic Ocean during summer, J. Geophys. Res., 106, 32 111-32 123, 2001. 